\title{
Sensory Innervation of the Nonspecialized Connective Tissues in the Low Back of the Rat
}

\author{
Sarah M. Corey ${ }^{a, e} \quad$ Margaret A. Vizzard ${ }^{a, b} \quad$ Gary J. Badger ${ }^{d}$ \\ Helene M. Langevin ${ }^{a, c}$ \\ Departments of a Neurology, ${ }^{b}$ Anatomy and Neurobiology, ${ }^{c}$ Orthopaedics and Rehabilitation and \\ ${ }^{\mathrm{d}}$ Medical Biostatistics, and eNeuroscience Graduate Program, University of Vermont, Burlington, Vt., USA
}

\section{Key Words}

Connective tissue $\cdot$ Innervation - Low back pain •

Musculoskeletal pain · Fascia

\begin{abstract}
Chronic musculoskeletal pain, including low back pain, is a worldwide debilitating condition; however, the mechanisms that underlie its development remain poorly understood. Pathological neuroplastic changes in the sensory innervation of connective tissue may contribute to the development of nonspecific chronic low back pain. Progress in understanding such potentially important abnormalities is hampered by limited knowledge of connective tissue's normal sensory innervation. The goal of this study was to evaluate and quantify the sensory nerve fibers terminating within the nonspecialized connective tissues in the low back of the rat. With 3-dimensional reconstructions of thick (30-80 $\mu \mathrm{m})$ tissue sections we have for the first time conclusively identified sensory nerve fiber terminations within the collagen matrix of connective tissue in the low back. Using dye labeling techniques with Fast Blue, presumptive dorsal root ganglia cells that innervate the low back were identified. Of the Fast Blue-labeled cells, $60-88 \%$ also expressed calcitonin
\end{abstract}

gene-related peptide (CGRP) immunoreactivity. Based on the immunolabeling with CGRP and the approximate size of these nerve fibers $(\leq 2 \mu \mathrm{m}$ ) we hypothesize that they are A $\delta$ or $C$ fibers and thus may play a role in the development of chronic pain.

Copyright $\odot 2011$ S. Karger AG, Basel

\section{Introduction}

The etiology of nonspecific musculoskeletal pain including low back pain is poorly understood [Deyo and Weinstein, 2001; Borg-Stein and Wilkins, 2006]. In particular the role played by the 'nonspecialized' loose and dense connective tissues forming the fascial planes of the back has received very little attention to date. To fully un-

\section{Abbreviations used in this paper}

CGRP Calcitonin gene-related peptide

DIC Differential interference contrast

DRG Dorsal root ganglia

\section{KARGER}

() 2011 S. Karger AG, Basel

Fax +4161306 1234

E-Mail karger@karger.ch

www.karger.com
Accessible online at: www.karger.com/cto
Dr. Sarah M. Corey

Given C423, Department of Neurology

University of Vermont

Burlington, VT 05405 (USA)

Tel. +1 802656 4526, E-Mail scorey@uvm.edu 
derstand whether connective tissues could be a potential source of pain, the innervation must first be established. The sensory innervation of specialized connective tissues of joints [Hanesch et al., 1997; Ohtori et al., 2003; Fernihough et al., 2005; Saxler et al., 2007; Strickland et al., 2008], tendons [Bjur et al., 2005; Danielson et al., 2006], and the dura [O'Connor and van der Kooy, 1988; Messlinger et al., 1993] support a role for connective tissue in pain generation. However, a major hurdle in establishing a role for connective tissue pathology in low back pain is that the intrinsic sensory innervation of 'nonspecialized' loose and dense connective tissue is not firmly established. Electrophysiological studies in rats showed evidence of functional innervation of the paraspinal connective tissues of the sacrum [Bove and Light, 1995] and the thoracolumbar fascia [Taguchi et al., 2008]. Furthermore, some descriptive and immunohistochemical studies have reported that sensory nerves are present in the connective tissues of the low back [Stilwell, 1957; Yahia et al., 1992; Reinert et al., 1998], although others have not found innervation [Bednar et al., 1995]. A particular challenge to studying the innervation of connective tissue is that nerve fibers within connective tissue could be 'en passant' on their way to the skin or muscles, branching and/or terminating within the tissue itself [Bove and Light, 1995]. However, the techniques used in previously published histological studies were not specific for sensory nerve fibers and did not clearly demonstrate the presence of nerve fiber endings [Stilwell, 1957; Yahia et al., 1992; Bednar et al., 1995; Reinert et al., 1998]. For most studies, thin $(4-6 \mu \mathrm{m})$ tissue sections were used where it was not possible to distinguish between a true nerve ending and an ending that was cut as a result of tissue processing [Stilwell, 1957; Yahia et al., 1992; Reinert et al., 1998].

Our goal in this study is to evaluate the presence of sensory innervation within nonspecialized connective tissues in the low back of the rat using a combination of confocal microscopy and retrograde tracing experiments. To establish whether the sensory innervation may be important for pain, we characterized the presence of nerve fibers containing calcitonin gene-related peptide (CGRP), a neuropeptide known to be involved in pain processing and persistence of pain through neurogenic inflammation [McMahon, 1996; Mense, 2001]. We used a rat model because, with the exception of the pannicular muscle deep to the subdermis, the tissue structure of the low back is similar in rodents and humans.

\section{Methods}

\section{Identification of Nerve Terminals}

To optimize tissue sectioning and nerve fiber visualization, a number of methods were used. Transverse sections (perpendicular to the skin) including dermis, connective tissues, and deep back muscles allowed for all of the layers to be visualized but had the disadvantage of cutting the nerves perpendicular to their predominant orientation (parallel to the plane of the skin). Dissection of whole tissue mounts along the longitudinal planes with scissors allowed for the isolation of the different types of tissue but created an unacceptable amount of tissue damage that interfered with the interpretation of the microscopy images. We finally opted to cut thick sections of frozen tissue on a cryostat in the longitudinal plane which had the advantage of preserving the tissue architecture and also allowed the visualization of nerves and nerve terminals within the longitudinal tissue layers. A limitation of this method was that we could not consistently orient the sectioning plane parallel to the tissue layers. Therefore, due to the close apposition, it was not technically possible with this method to completely isolate the areolar connective tissue from the surrounding dense connective tissue layers.

\section{Dissection}

Adult male Wistar rats ( $\mathrm{n}=5 ; 350 \mathrm{~g})$ were purchased from Charles River Laboratories (Saint Constant, Que., Canada) and all protocols were approved by the Institutional Animal Care and Use Committee at the University of Vermont. Rats were euthanized and perfused with heparin and $4 \%$ paraformaldehyde. A $1 \times 1 \mathrm{~cm}$ block of tissue was excised bilaterally from the low back (L1 to L6, lateral of the spine) including all tissues from the dermis to the deep spinal muscles (fig. 1a). Tissue blocks were postfixed with $4 \%$ paraformaldehyde for $24 \mathrm{~h}$ and placed in $30 \%$ sucrose for a minimum of $24 \mathrm{~h}$ before sectioning on a freezing microtome. Once in sucrose, the tissue block was separated into 2 pieces, 1 superficial (piece 1) and 1 deep (piece 2), by cutting at the cleavage plane (approximately $1.5-2 \mathrm{~mm}$ thick) between the pannicular muscle and the deep back muscle (fig. 1b). The superficial piece was placed on the freezing microtome skin side down and the deep piece was placed muscle side down (fig. 1c). The purpose of this method was to ensure that the first tissue to be cut in both cases was the areolar (loose) connective tissue forming the intermuscular plane between the pannicular and deep muscles. We then cut thick (30-80 $\mu \mathrm{m})$ sections through the areolar connective tissues, stopping when we reached muscle tissue (superficial, pannicular muscle for piece 1 and deep back muscle for piece 2). In this way, the dermal and subdermal tissue was excluded from sectioning.

\section{Immunofluorescence}

Thick connective tissue sections were placed in individual wells of a standard low binding 24 -well plate. Sections were permeabilized with phosphate-buffered saline with $1 \%$ bovine serum albumin with $0.5 \%$ Triton X-100 (Sigma, St. Louis, Mo., USA) for $2 \mathrm{~h}$. These floating sections were blocked with $10 \%$ normal goat serum (Vector Labs, Burlingame, Calif., USA) for $30 \mathrm{~min}$ before application of the primary antibody overnight. After washing, Alexa 488 or 568 (Invitrogen) secondary antibody was applied for $30 \mathrm{~min}$. Primary antibodies included protein gene product 9.5 (PGP9.5; Biogenesis, Poole, UK), CGRP (Bachem, Torrance, 

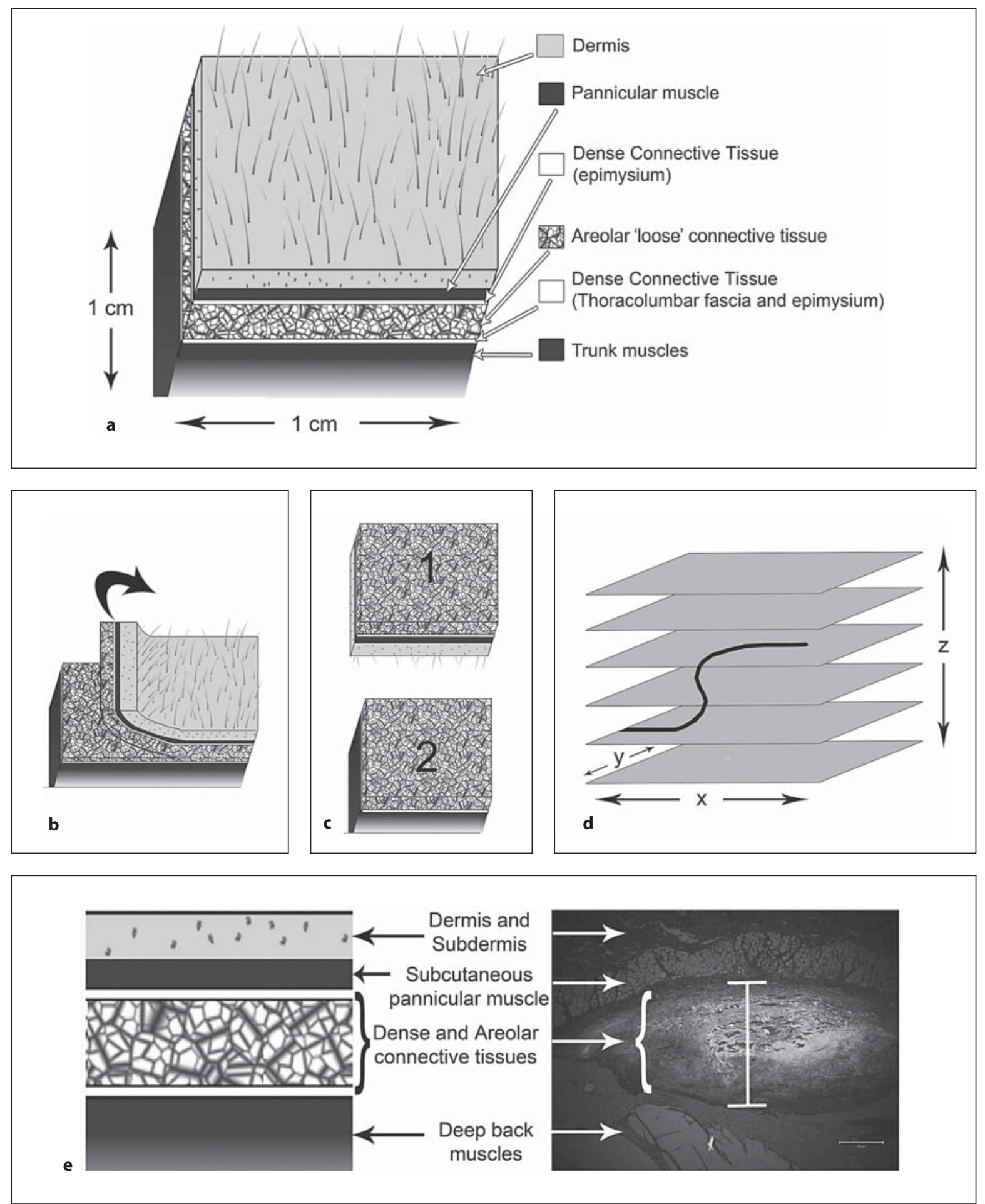

Fig. 1. Methods for identification of nerve endings. a Anatomy of the tissue layers of the low back including skin, subcutaneous muscle, dense connective tissue, areolar connective tissue, dense connective tissue, and the deep back muscles. b, c For thick tissue sectioning, the areolar and dense connective tissues were isolated by separating the tissue block as shown. d Collection of a stack of images through the $\mathrm{z}$ plane (orthogonal to the section) with confocal microscopy allows for nerve fibers and their surrounding tissues to be evaluated. e Histological section of tissues of the low back in the region of Fast Blue injection. Fast Blue is visualized in UV and is white in this image. The vertical bar at the center of the image indicates the spread of tracer within the areolar and dense connective tissues and not into the muscle tissue or dermis. Scale bar $=200 \mu \mathrm{m}$. 
Calif., USA), and collagen-1 (Sigma). For double labeling, sections were first stained with CGRP to label sensory nerve fibers and then stained with a collagen-1 antibody to label collagen fibers. Negative controls consisted of isotype-matched controls and the omission of primary antibody.

\section{Confocal Microscopy}

A Zeiss LSM 510 META scanning laser microscope was used to capture confocal images at $20 \times(0.75 \mathrm{NA})$ and $25 \times(0.8 \mathrm{NA})$ in tissue sections stained with PGP9.5, CGRP, and/or collagen-1. To identify a terminating nerve fiber, a CGRP-expressing fiber was followed to the point where immunolabeling ceased, within the connective tissue matrix. This was considered a potential nerve ending. To establish antibody penetration, the area above, below, and beyond the ending was visually scanned for the presence of CGRP labeling at a similar depth elsewhere in the tissue section. To confirm whether the fiber was actually terminating, a confocal $\mathrm{z}$ stack of optical images was collected from above and below the potential nerve ending (fig. 1d). When collagen was present above, below, and beyond the CGRP-positive fiber, and $\mathrm{z}$ banding (indicating the presence of muscle fibers) was absent, this was considered to be a nerve ending within connective tissue. Collagen fibers were identified visually with differential interference contrast (DIC) and collagen-1 antibody labeling.

\section{Quantification}

Retrograde Labeling and Immunofluorescence

For quantification, 12 adult male Wistar rats (350 g) were anesthetized with isoflurane $(2-5 \%)$ in oxygen; the rats were shaved and $10 \mu \mathrm{l}$ of Fast Blue (4\% w/v; EMS Chemie, Zurich, Switzerland) retrograde tracer was injected (28-gauge syringe) into the subcutaneous cleavage plane approximately $3 \mathrm{~mm}$ deep to the skin surface, $1 \mathrm{~cm}$ lateral of the spine at L3 (randomized by side). To minimize the leakage of Fast Blue into the needle path, a small pocket of air was drawn into the needle before and after the $10 \mu \mathrm{l}$ of Fast Blue [Hanesch and Heppelmann, 1995]. This method of measuring Fast Blue leakage was confirmed in cadaver tissue and with tissue collection at the end of the experiment. After 1 week, tissue was collected from both the low back and the spinal cord with associated dorsal root ganglia (DRG) from T8 through L4. To isolate the tissues of the low back, a tissue block was excised from the skin to the deep back muscles to determine the extent of the tracer spread within the connective tissues (fig. 1e). This tissue was fixed in $4 \%$ paraformaldehyde and processed for histology. The DRG were dissected, fixed in $4 \%$ paraformaldehyde, immersed in sucrose, embedded in Optimum Cutting Temperature compound (Sakura; Torrance, Calif., USA), and sectioned $(16 \mu \mathrm{m})$ on a cryostat. Standard immunohistochemical and immunofluorescent techniques were used with CGRP antibody to identify sensory nerve cell bodies within the DRG (see above). Only DRG from rats where the tracer had remained within the connective tissues (as determined with histological analysis of tissues from the low back; fig. 1e) and not become systemic (evaluated by examining lumbar and cervical DRG from both the injected side and the noninjected side) were further analyzed in this study. In 6 of the 12 Fast Blue-injected animals, tracer remained within the connective tissues (in 2 animals Fast Blue was found in the surrounding tissues and in 4 animals Fast Blue became systemic).
Imaging

To quantify the Fast Blue-labeled cells in the DRG, 16- $\mu \mathrm{m}$ tissue sections were cut $(30 \mu \mathrm{m}$ between each section to minimize potential double counting) and visualized with an Olympus BX51 fluorescent microscope. Each tissue section was immunohistochemically stained for CGRP expression. Quantification of Fast Blue and CGRP expression in DRG was performed by an individual blinded to the DRG level and the tracer-injected/uninjected side. DRG exhibiting Fast Blue with a visible nucleus were counted as Fast Blue-positive cells. The number of Fast Blue-labeled cells that also expressed CGRP was evaluated at each spinal cord level (T8 to L4) by switching between the broad UV channel and the 545 excitation filter.

\section{Data Analysis}

Repeated measures analysis of variance [PROC MIXED; SAS, 2008] was used to compare the mean number of labeled cells across spinal cord levels. Because the variance was heterogenic across levels, a square root transformation was used to stabilize the variance prior to analysis [Box et al., 1978]. Pairwise comparisons among levels utilized Fisher's LSD procedure. The quantification of relative expression of CGRP in Fast Blue-labeled cells for each level was expressed as the mean percentage expression across animals. This computation of relative expression of CGRP was limited to the 4 spinal levels that had reasonable numbers (an average greater than 10) of Fast Blue-labeled cells. Graphs were created with GraphPad Prism Version 5 (GraphPad Software, San Diego, Calif., USA).

\section{Results}

\section{Nerve Fibers in the Connective Tissues of the}

Low Back

DIC imaging can be used to visually differentiate the areolar connective tissue (fig. 2a), dense connective tissue (fig. 2b), and muscle (fig. 2c). Areolar connective tissue is visualized as a loosely organized network of collagen fibers. Dense connective tissue is also composed of collagen, but the structure is more tightly organized, and muscle tissue is recognized by its characteristic $\mathrm{z}$ banding (fig. 2c; arrow indicates area of prominent $\mathrm{z}$ banding). Nerve fibers identified with PGP9.5 (pan neuronal marker) were found within each of these types of tissue (fig. $2 d-$ f). CGRP antibody was used to further identify sensory nerve fibers that may contribute to pain processing. Within the collagen matrix of the connective tissues of the low back we confirmed the presence of sensory nerve fiber terminations labeled with CGRP. These terminating nerve fibers were surrounded by collagen matrix visualized with DIC (fig. 3) or with direct labeling by a collagen-1 antibody in combination with DIC (fig. 4). Confocal microscopy image slices through the $\mathrm{z}$ plane of the tissue confirmed the presence of connective tissue superficial and deep to the nerve fiber termination. A 

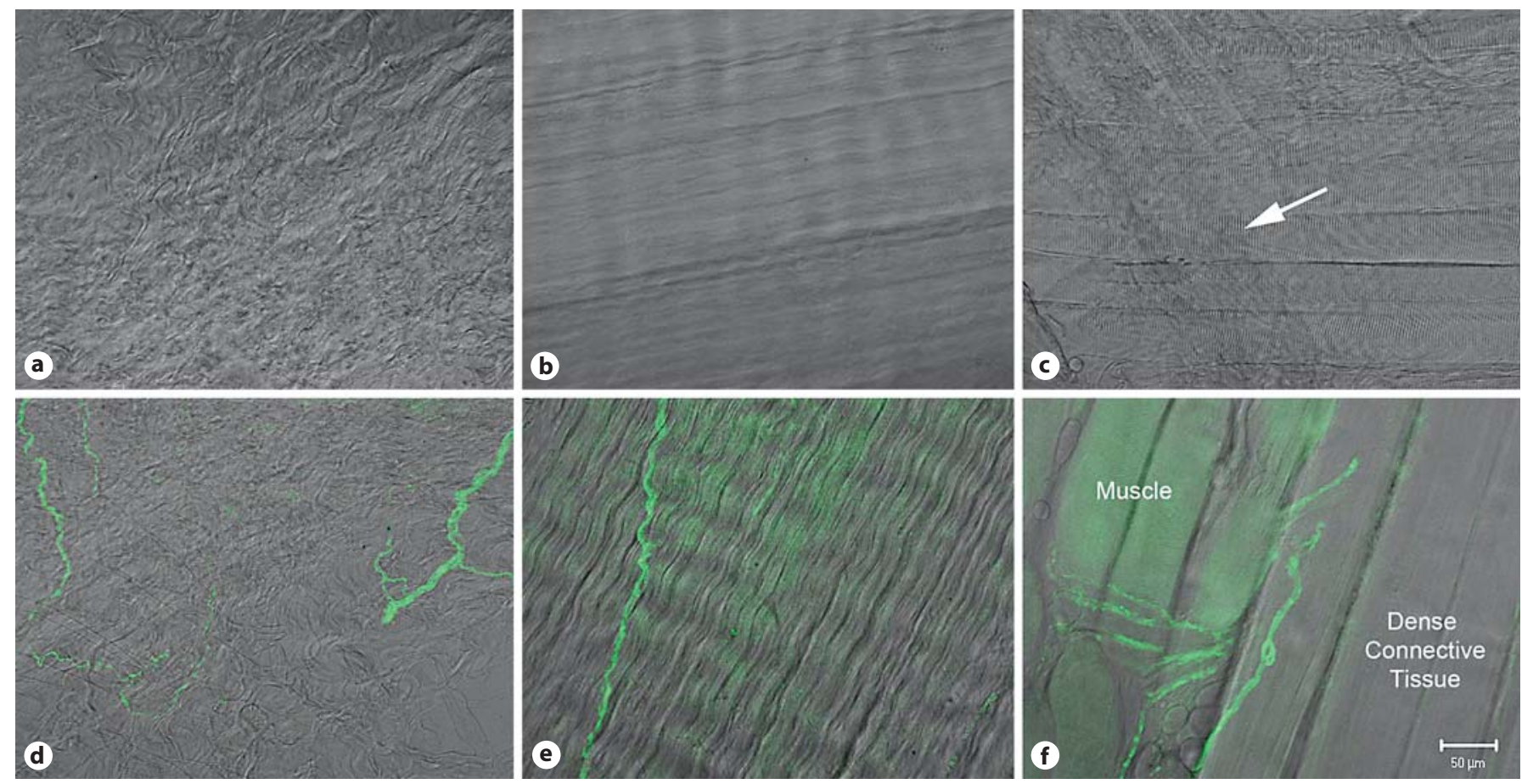

Fig. 2. PGP9.5 (pan neuronal marker) labeling and differential interference contrast (DIC) imaging. Single slices from confocal optical z stacks of areolar connective tissue (a) dense connective tissue (b) and muscle (c) in the low back of the rat visualized with
DIC. Examples of DIC combined with PGP9.5 antibody labeling of areolar connective tissue (d), dense connective tissue (e) and muscle and dense connective tissue (f). Lens: PlanApochromat $\times 20$ (0.75 N.A.). Scale bar $=50 \mu \mathrm{m}$. merged 3-dimensional projection image creating a visual representation of the full extent of the CGRP-labeled nerve fiber is shown in figure $3 \mathrm{a}, \mathrm{b}$ and in figure $4 \mathrm{a}$. A gallery of optical sequential slices from the confocal $\mathrm{z}$ stack also demonstrates the presence of collagen fibers above and below the nerve fiber termination (fig. 3c, 4b). Circles indicate the location of the nerve fiber termination and collagen present in slices above and below the CGRP-labeled nerve fiber. An orthogonal image of the 3-dimensional reconstruction of the $\mathrm{z}$ plane of the tissue shows the nerve fiber (red) ending 'sandwiched' between layers of collagen (fig. 4c).

\section{Fast Blue and CGRP DRG Quantification}

Figure 5 shows the labeling of Fast Blue cells within the DRG with the UV channel $(400 \mathrm{~nm})$ in addition to the expression of CGRP in the same cells viewed with the red $(545 \mathrm{~nm})$ channel with a fluorescent microscope. One week after injection, Fast Blue retrograde tracer was transported from the nonspecialized connective tissues of the low back ( $1 \mathrm{~cm}$ lateral of L3) to the DRG. Dissected tissues from the low back were evaluated histologically for tracer spread. Of the 6 animals where Fast Blue remained within the nonspecialized connective tissues, Fast Blue-labeled cell bodies were counted in ipsilateral DRG from T8 to L4. Fast Blue labeling was only present from T9 to L3 DRG with a mean $( \pm \mathrm{SE})$ of $90.7 \pm 16.6$ Fast Blue-positive cells per animal. A nonuniform distribution of tracer was found across the spinal cord levels (repeated measures ANOVA; $p \leq 0.0001$ ). Figure 6 (light gray columns) shows that a significantly greater number of Fast Blue-positive cells was found at the T13 and L1 DRG compared with other levels from T8 to L4 (Fisher's LSD; $\mathrm{p}<0.05$ ).

The majority of Fast Blue-labeled DRG cells from T9 to L3 also stained immunohistochemically for CGRP (fig. 5). Figure 6 (dark gray columns) shows the distribution of CGRP expression within the population of Fast Blue-expressing cells, with a mean $( \pm$ SE) of $67.8 \pm 12.5$ DRG cells labeled with both Fast Blue and CGRP. The percentage of Fast Blue-positive cells that also expressed CGRP was 60$88 \%$ (at spinal cord levels with more than an average number of 10 Fast Blue-positive cells present). At the T13 and L1 levels, where the majority of Fast Blue cells were located, CGRP expression was 88 and 73\%, respectively (fig. 6). 

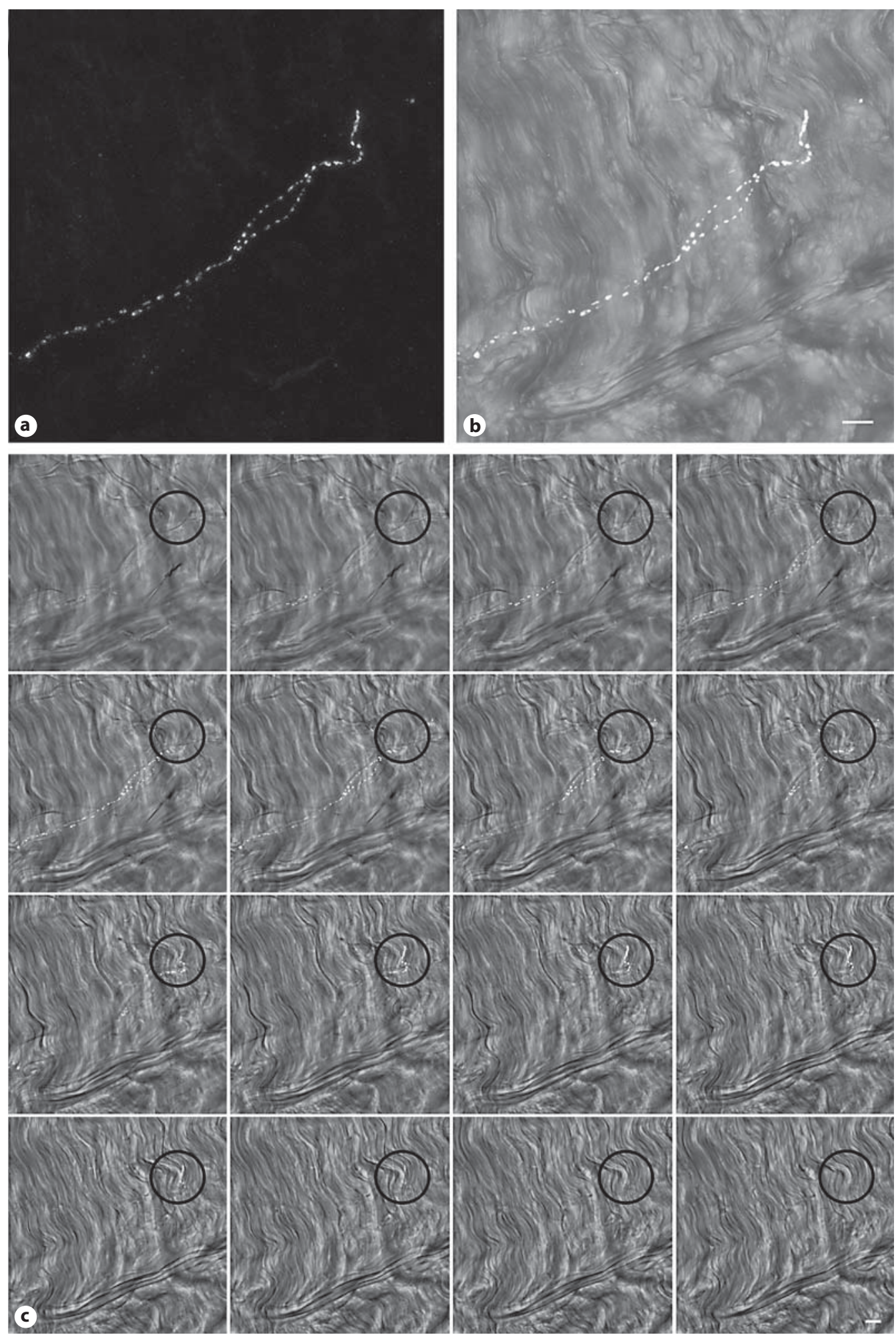

Fig. 3. Confocal z series of 34 optical slices representing $25.4 \mu \mathrm{m}$ of tissue. a Full projection image of the CGRP-positive nerve fiber (white). b Projection of a subset of optical tissue slices (left to right) to visualize the nerve fiber within the collagen matrix with DIC (gray scale). c Gallery of individual slices (every other slice)

from the optical $\mathrm{z}$ stack demonstrating collagen above and below the CGRP sensory nerve fiber. Black circles indicate the location of the nerve ending. The lens was a PlanApochromat $\times 25(0.8$ NA) with a zoom factor of 2.6. Scale bars $=10 \mu \mathrm{m}$. 

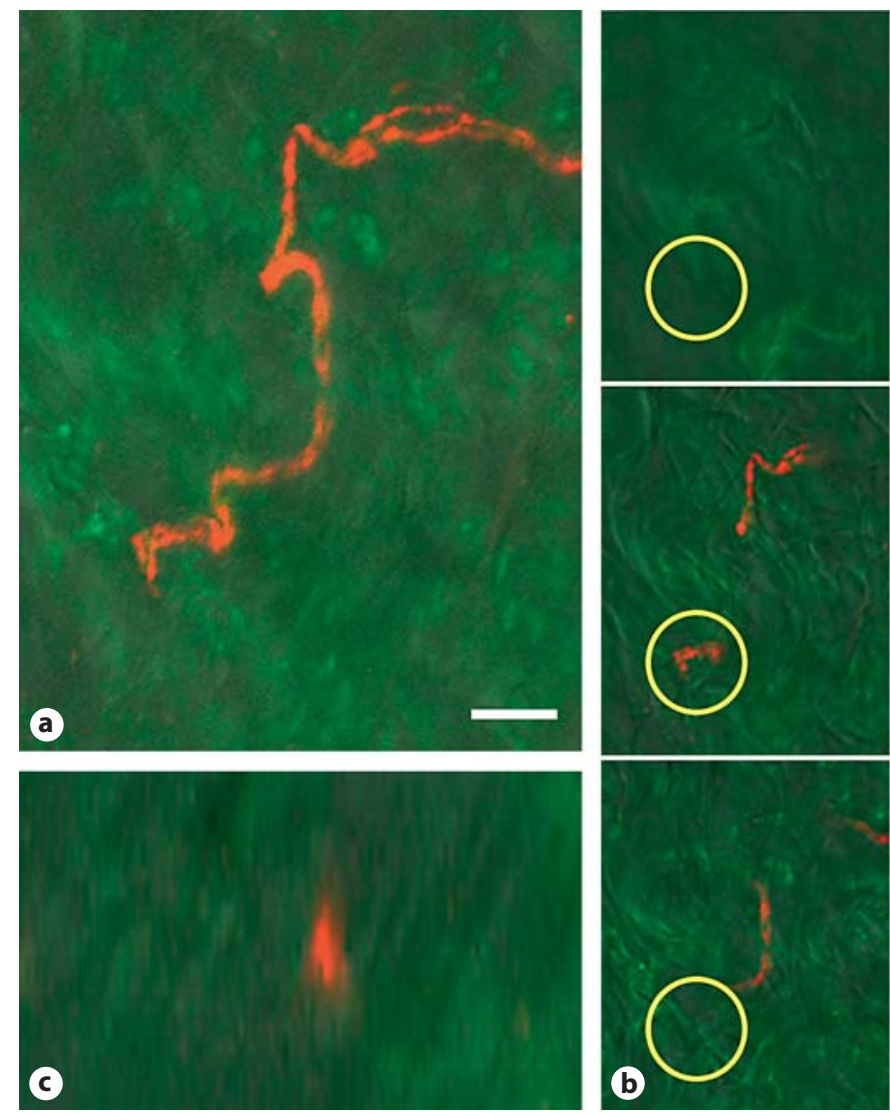

Fig. 4. Confocal z series of 25 sections representing $35.4 \mu \mathrm{m}$ of tissue. a Projection image of the 9 th to 18 th optical tissue sections (13.3 $\mu \mathrm{m}$ thickness) to show the full nerve fiber. Sensory nerve is labeled with CGRP (red) and collagen is labeled with antibody (collagen-1; green) and visualized with DIC (gray scale). b Gallery (left to right) showing every other slice from the optical $z$ stack

\section{Discussion}

The majority of chronic low back pain research to date has focused on disorders of the spine [Deyo and Weinstein, 2001; Borg-Stein and Wilkins, 2006]. Another hypothesis concerns altered central nervous system mechanisms where continuing pain signals are relayed to the brain even though an initial tissue or nerve injury may have healed. However, neither of these hypotheses has been able to fully explain low back pain chronicity. One major gap in the research includes the contribution of musculoskeletal tissues (muscle and nonspecialized connective tissues) of the low back lateral to the spine. Most studies that have addressed this topic have focused on the contribution of the muscle tissue [Bove and Light, 1995; Danneels et al., 2001, 2002; Taguchi et al., 2007, 2008; Wallwork et al., 2009]. A few studies have evaluated the potential role of connective

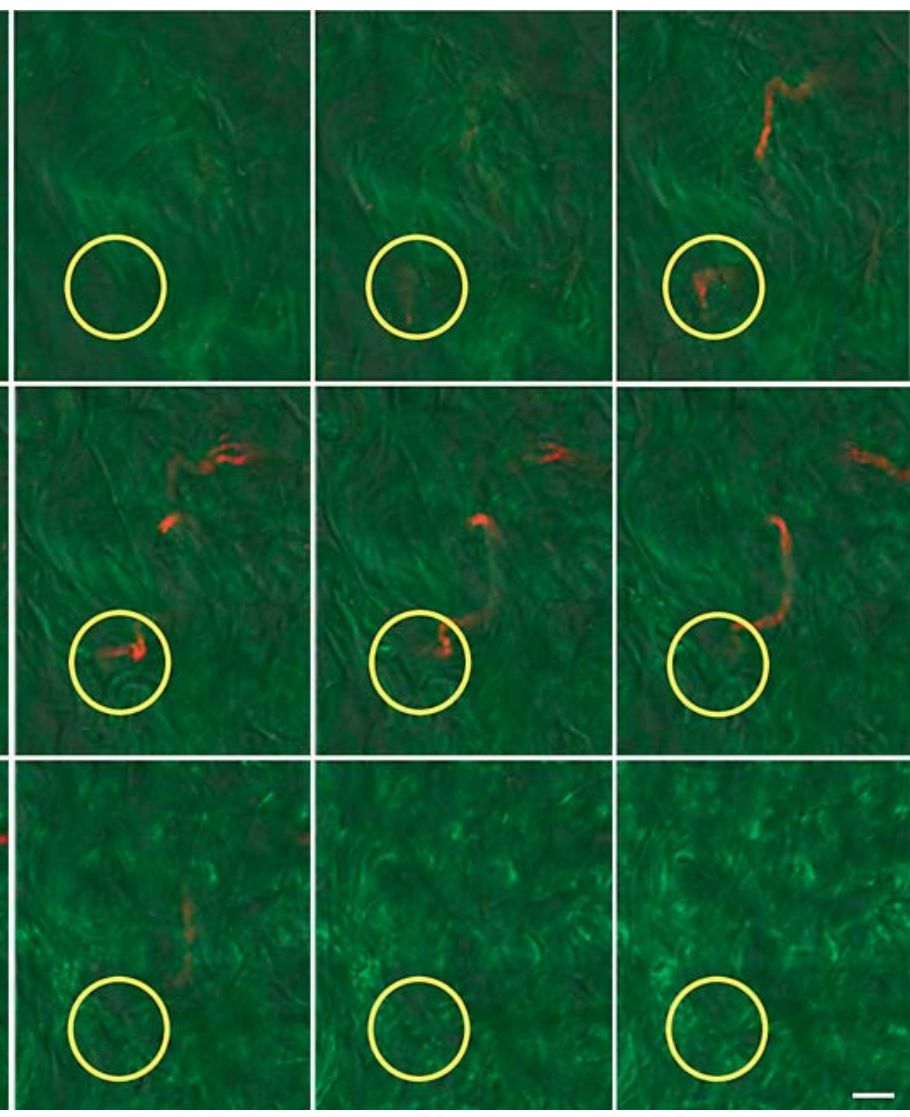

demonstrating collagen above and below the CGRP-expressing sensory nerve fiber. Yellow circles outline the termination of the nerve fiber. c Orthogonal view of the $\mathrm{z}$ plane of the tissue at the nerve ending. The lens used was a PlanApochromat $\times 20(0.75$ NA) with a zoom factor of 2.6. Scale bars $=10 \mu \mathrm{m}$.

tissues with electrophysiology [Bove and Light, 1995; Taguchi et al., 2008], and a recent human study used ultrasound to measure changes in the structure of the nonspecialized connective tissues of the low back associated with chronic low back pain [Langevin et al., 2009].

The pathophysiology of nonspecialized connective tissues, their relationship to low back pain, and other chronic musculoskeletal pain conditions is not well understood but may include fibrosis, chronic inflammation, and altered sensitivity through neuroplastic changes [Langevin and Sherman, 2007]. As a first step to investigate the role of connective tissue innervation in the development of low back pain, we aimed to characterize the normal innervation of the connective tissues of the low back. This study for the first time demonstrates the presence of terminating sensory CGRP-labeled nerve fibers within the collagen matrix of the nonspecialized connec- 

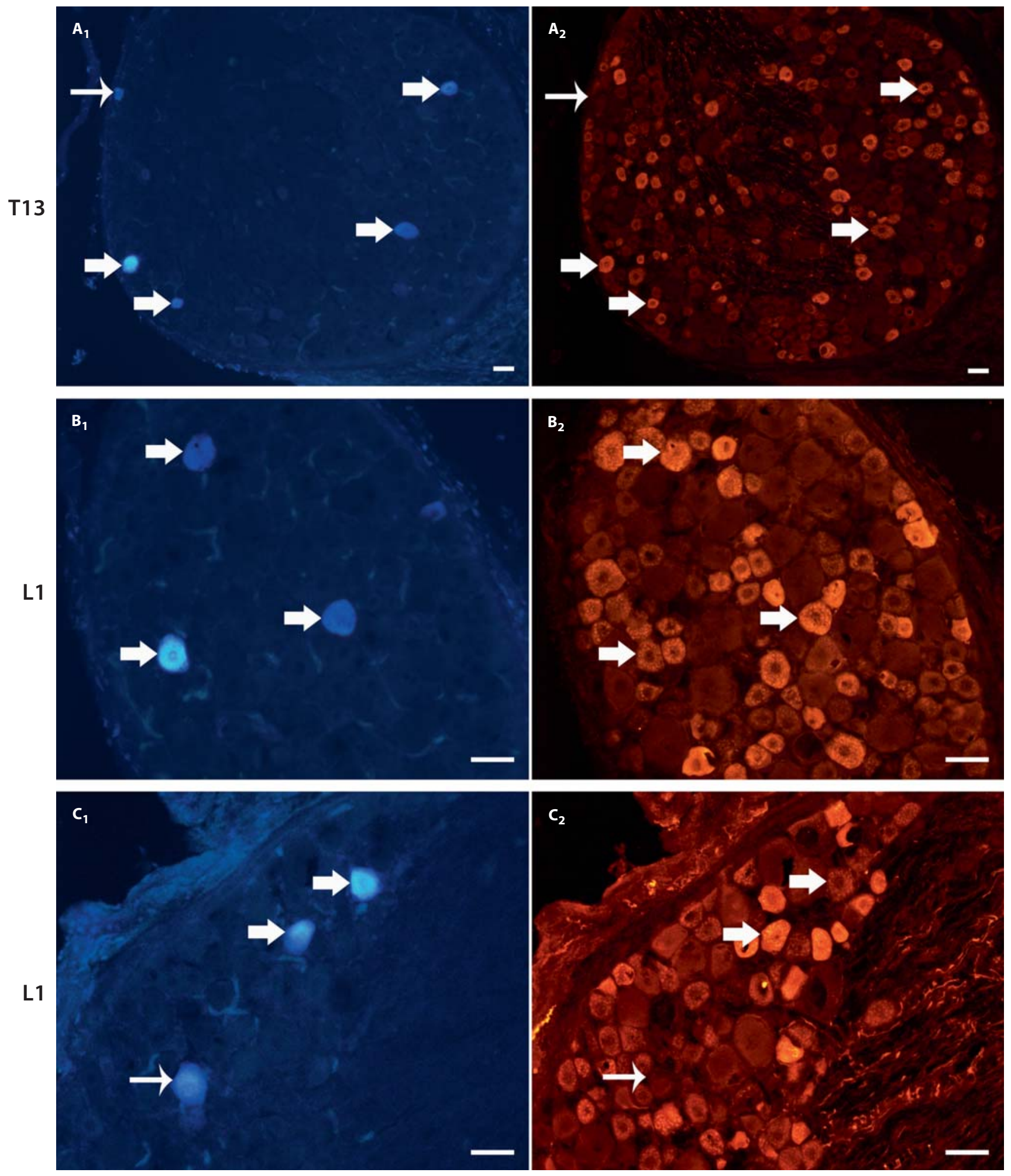

Fig. 5. Fast Blue retrograde tracer and CGRP expression within the DRG. Examples of DRG tissue sections labeled with Fast Blue $\left(\mathbf{A}_{\mathbf{1}}, \mathbf{B}_{\mathbf{1}}\right.$, and $\left.\mathbf{C}_{\mathbf{1}}\right)$ and corresponding staining of each section with $\operatorname{CGRP}\left(\mathbf{A}_{\mathbf{2}}, \mathbf{B}_{\mathbf{2}}\right.$, and $\left.\mathbf{C}_{\mathbf{2}}\right)$. Thick arrows indicate cells labeled with both Fast Blue and CGRP and thin arrows demonstrate Fast Blue-positive cell bodies that do not express CGRP. DRG levels are T13 for section $\mathbf{A}$ and L1 for sections $\mathbf{B}$ and $\mathbf{C}$. Scale bars $=50$ $\mu \mathrm{m}$. 


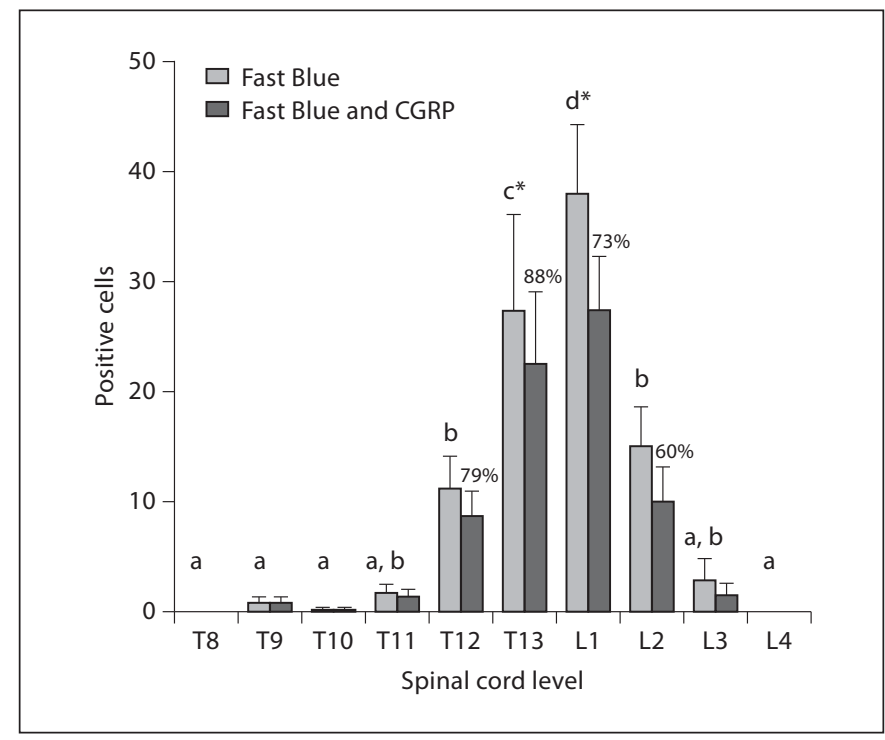

Fig. 6. Quantitative analysis of Fast Blue- and CGRP-labeled cells at T8-L4 spinal cord levels. Light gray bars indicate the distribution of counted Fast Blue-labeled cells (mean with SEM) innervating the connective tissues (tracer injected lateral to L3). Columns sharing a letter are not significantly different from each other. Spinal cord levels indicated by $\left(^{*}\right)$ are significantly different from all other levels (Fisher's LSD; $\mathrm{p}<0.05$ ). The expression of CGRP (dark gray bars) within the population of Fast Blue-labeled cells (mean with SEM) is indicated by the percentages over the dark gray bars.

tive tissues in the low back of the rat. Here we showed that nerve fibers terminate within these connective tissues with two complementary methods: confocal microscopy of thick tissue sections and quantification with retrograde tracer. Colabeling of DRG cells projecting from the connective tissues of the low back with CGRP indicates that these tissues may be involved in nociception.

These CGRP-immunoreactive nerve endings have a small diameter $(\leq 2 \mu \mathrm{m})$ devoid of surrounding encapsulated collagen structures and thus appeared to be 'free' nerve endings. Based on the approximate size of these nerve fibers, we hypothesize that they are $\mathrm{A} \delta$ and/or $\mathrm{C}$ fibers. There were some CGRP-labeled fibers associated with blood vessels, but they were not observed to terminate. A range of 1-19 CGRP-positive free nerve endings were observed in a low-power field of view. However, precise quantification of the density of nerve fibers and nerve fiber terminations within tissue sections was not possible for the following reasons: first, the number of nerve fibers within a nerve bundle (fig. 2d; right) was not always discernible; second, it was not always possible to determine whether all the fibers in the field of view were actually terminating within that specific type of tissue (fig. 2e), and third, some of the fibers branched into multiple types of tissue (fig. 2f). Therefore, to gain a better understanding of the number of terminals within this tissue, we used retrograde labeling as a surrogate method to quantify sensory innervation of the nonspecialized connective tissues of the low back. Fast Blue (retrograde dye tracer) is specifically taken up at nerve fiber endings, unlike a lipophilic dye that diffuses across all nerve fiber membranes [Kobbert et al., 2000]. This method allowed for the quantification of the intrinsic connective tissue sensory innervation. Overall, the innervation of these tissues appears to be substantial. With the injection of Fast Blue at the level of the L3 vertebrae, the greatest numbers of retrogradely labeled primary sensory neurons were observed in the L1 and T13 DRG, a result consistent with electrophysiology studies involving mechanical stimulation of paraspinal tissue structures of the sacrum [Bove and Light, 1995] and tissue structures of the low back [Taguchi et al., 2008]. While the significance of this innervation cannot be determined directly from this study, the innervation is comparable to the numbers $(82 \pm 5$; DRG cells labeled with Fast Blue) found in the connective tissues of the knee joint [Strickland et al., 2008], a tissue with a well-established role in inflammatory pain. After injection with retrograde tracer the multifidus muscle also exhibited a similar expression profile, with a rostral shift from the site of injection to the DRG where the largest number of tracerlabeled cells were located [Taguchi et al., 2007].

A majority of Fast Blue-labeled DRG cells projecting from the nonspecialized connective tissues of the low back also expressed CGRP, a neuropeptide known to be involved in neurogenic inflammation [Hughes and Brain, 1991; McMahon, 1996; Mense, 2001]. Interestingly, in the knee joint, $76.7 \%$ of Fast Blue-labeled cells projecting from the connective tissues also expressed CGRP [Fernihough et al., 2005], a value comparable to the range of $60-88 \%$ found in this study. In the skin, an average of $34.9 \%$ neurons counted expressed CGRP [Tsukagoshi et al., 2006]. In muscle, $21.6 \%$ (longissimus muscle) and $32.6 \%$ (trapezius muscle) of retrogradely labeled cells demonstrated CGRP expression (with a total number of Fast Blue-labeled cells similar to that observed in our study) [Tsukagoshi et al., 2006]. In addition, a study of the gastrocnemius-soleus muscle revealed that a greater number of fibers expressing CGRP were within the connective tissues associated with the muscle as compared to the muscle itself [Reinert et al., 1998].

Taken together the results of the current study suggest that the sensory nerve fibers observed in the nonspecial- 
ized connective tissues of the low back may contribute to pain perception. A limitation of this method is the inability to distinguish between fibers terminating in the areolar versus the dense connective tissues due to their close apposition. Further work is ongoing to determine whether the structural innervation of these connective tissues is important for functional changes associated with neurogenic inflammation and persistent pain.

\section{Acknowledgements}

We are grateful to Nicole Bouffard and Cathryn Koptiuch for their technical assistance and to Dr. Robert Hamill, Dr. Gary Mawe, and Dr. Felix Eckenstein for their guidance and advice.

This research was supported by a grant from the NIH (NCCAM) (1F31AT005559-01).

\section{References}

Bednar, D.A., F.W. Orr, S. G.T. (1995) Observations on the pathomorphology of the thoracolumbar fascia in chronic mechanical back pain: a microscopic study. Spine 20: 11611164.

Bjur, D., H. Alfredson, S. Forsgren (2005) The innervation pattern of the human Achilles tendon: studies of the normal and tendinosis tendon with markers for general and sensory innervation. Cell Tissue Res 320: 201-206.

Borg-Stein, J., A. Wilkins (2006) Soft tissue determinants of low back pain. Curr Pain Headache Rep 10: 339-344.

Bove, G.M., A.R. Light (1995) Unmyelinated nociceptors of rat paraspinal tissues. J Neurophysiol 73: 1752-1762.

Box, G., W. Hunter, J. Hunter (1978) Statistics for Experimenters. New York, Wiley.

Danielson, P., H. Alfredson, S. Forsgren (2006) Distribution of general (PGP 9.5) and sensory (substance P/CGRP) innervations in the human patellar tendon. Knee Surg Sports Traumatol Arthrosc 14: 125-132.

Danneels, L.A., P.L. Coorevits, A.M. Cools, G.G. Vanderstraeten, D.C. Cambier, E.E. Witvrouw, C.H. De (2002) Differences in electromyographic activity in the multifidus muscle and the iliocostalis lumborum between healthy subjects and patients with sub-acute and chronic low back pain. Eur Spine J 11: 13-19.

Danneels, L.A., G.G. Vanderstraeten, D.C. Cambier, E.E. Witvrouw, J. Bourgois, W. Dankaerts, H.J. De Cuyper (2001) Effects of three different training modalities on the cross sectional area of the lumbar multifidus muscle in patients with chronic low back pain. Br J Sports Med 35: 186-191.

Deyo, R.A., J.N. Weinstein (2001) Low back pain. N Engl J Med 344: 363-370.

Fernihough, J., C. Gentry, S. Bevan, J. Winter (2005) Regulation of calcitonin gene-related peptide and TRPV1 in a rat model of osteoarthritis. Neurosci Lett 388: 75-80.

-Hanesch, U., B. Heppelmann (1995) A simple method for a specific retrograde labelling of dorsal root and sympathetic ganglion cells innervating the knee joint of the cat. J Neurosci Methods 63: 55-59.
-Hanesch, U., B. Heppelmann, R.F. Schmidt (1997) Quantification of cat's articular afferents containing calcitonin gene-related peptide or substance $\mathrm{P}$ innervating normal and acutely inflamed knee joints. Neurosci Lett 233: $105-108$

Hughes, S.R., S.D. Brain (1991) A calcitonin gene-related peptide (CGRP) antagonist (CGRP8-37) inhibits microvascular responses induced by CGRP and capsaicin in skin. Br J Pharmacol 104: 738-742.

Kobbert, C., R. Apps, I. Bechmann, J.L. Lanciego, J. Mey, S. Thanos (2000) Current concepts in neuroanatomical tracing. Prog Neurobiol 62: 327-351.

Langevin, H.M., K.J. Sherman (2007) Pathophysiological model for chronic low back pain integrating connective tissue and nervous system mechanisms. Med Hypotheses 68: 74-80.

Langevin, H.M., D. Stevens-Tuttle, J.R. Fox, G.J. Badger, N.A. Bouffard, M.H. Krag, J. Wu, S.M. Henry (2009) Ultrasound evidence of altered lumbar connective tissue structure in human subjects with chronic low back pain. BMC Musculoskelet Disord 10: 151.

McMahon, S.B. (1996) NGF as a mediator of inflammatory pain. Philos Trans R Soc Lond B Biol Sci 351: 431-440.

Mense, S. (2001) Pathophysiology of low back pain and the transition to the chronic state - experimental data and new concepts (in German). Schmerz 15: 413-417.

Messlinger, K., U. Hanesch, M. Baumgartel, B. Trost, R.F. Schmidt (1993) Innervation of the dura mater encephali of cat and rat: ultrastructure and calcitonin gene-related peptide-like and substance P-like immunoreactivity. Anat Embryol (Berl) 188: 219-237.

O'Connor, T.P., D. van der Kooy (1988) Enrichment of a vasoactive neuropeptide (calcitonin gene related peptide) in the trigeminal sensory projection to the intracranial arteries. J Neurosci 8: 2468-2476.
-Ohtori, S., K. Takahashi, T. Chiba, M. Yamagata, H. Sameda, H. Moriya (2003) Calcitonin gene-related peptide immunoreactive neurons with dichotomizing axons projecting to the lumbar muscle and knee in rats. Eur Spine J 12: 576-580.

Reinert, A., A. Kaske, S. Mense (1998) Inflammation-induced increase in the density of neuropeptide-immunoreactive nerve endings in rat skeletal muscle. Exp Brain Res 121: $174-180$.

SAS Institute (2008) SAS statistical software version 9. Cary, SAS Institute.

Saxler, G., F. Löer, M. Skumavc, J. Pförtner, U. Hanesch (2007) Localization of SP- and CGRP-immunopositive nerve fibers in the hip joint of patients with painful osteoarthritis and of patients with painless failed total hip arthroplasties. Eur J Pain 11: 67-74.

-Stilwell, D.L. Jr. (1957) Regional variations in the innervation of deep fasciae and aponeuroses. Anat Rec 127: 635-653.

Strickland, I.T., J.C. Martindale, P.L. Woodhams, A.J. Reeve, I.P. Chessell, D.S. McQueen (2008) Changes in the expression of NaV1.7, NaV1.8 and NaV1.9 in a distinct population of dorsal root ganglia innervating the rat knee joint in a model of chronic inflammatory joint pain. Eur J Pain 12: 564-572.

Taguchi, T., U. Hoheisel, S. Mense (2008) Dorsal horn neurons having input from low back structures in rats. Pain 138: 119-129.

Taguchi, T., V. John, U. Hoheisel, S. Mense (2007) Neuroanatomical pathway of nociception originating in a low back muscle (multifidus) in the rat. Neurosci Lett 427: 22-27.

Tsukagoshi, M., R.C. Goris, K. Funakoshi (2006) Differential distribution of vanilloid receptors in the primary sensory neurons projecting to the dorsal skin and muscles. Histochem Cell Biol 126: 343-352.

Wallwork, T.L., W.R. Stanton, M. Freke, J.A. Hides (2009) The effect of chronic low back pain on size and contraction of the lumbar multifidus muscle. Man Ther 14: 496-500.

-Yahia, L., S. Rhalmi, N. Newman, M. Isler (1992) Sensory innervation of human thoracolumbar fascia: an immunohistochemical study. Acta Orthop Scand 63: 195-197. 